\title{
The use of 2-dimensional gas chromatography to investigate the effect of rumen-protected conjugated linoleic acid, breed, and lactation stage on the fatty acid profile of sheep milk
}

\author{
E. Pellattiero, A. Cecchinato, F. Tagliapietra, ${ }^{1}$ S. Schiavon, and G. Bittante \\ Department of Agronomy, Food, Natural Resources, Animals and Environment (DAFNAE), University of Padova, Viale dell'Università 16, \\ 35020 Legnaro (PD), Italy
}

\begin{abstract}
In this study, 2-dimensional gas chromatography (GC $\times$ GC) was used to obtain a detailed fatty acid (FA) profile of sheep milk and to evaluate the effects of a rumen-protected conjugated linoleic acid (rpCLA) supply, breed, days in milk (DIM), sampling period, and number of lambs suckling on the FA profile. Twentyfour ewes, from 3 autochthonous breeds of the Veneto Alps (Brogna, Foza, and Lamon), were housed in 6 pens ( 2 pens/breed), according to DIM ( $38 \pm 23 \mathrm{~d})$ and body weight $(61 \pm 13 \mathrm{~kg})$. The ewes and their offspring of 3 pens ( 1 pen/breed) were fed ad libitum a total mixed ration (control), and the other animals received the same diet supplemented with $12 \mathrm{~g} / \mathrm{d}$ per ewe, plus $4 \mathrm{~g} / \mathrm{d}$ for each lamb older than $30 \mathrm{~d}$, of an rpCLA mixture. The study lasted $63 \mathrm{~d}$. Two composite milk samples for each ewe were prepared during the first and second months of the trial. The pooled milk samples were analyzed in duplicate for FA profile by 2-dimensional gas chromatography, which allowed us to obtain a detailed FA profile of sheep milk, with 170 different FA detected, including many that were present in small concentrations. The milk relative proportions of individual FA, groups of FA, or FA indices were analyzed by PROC MIXED of SAS (SAS Institute Inc., Cary, NC), considering diet, breed, DIM, and sampling period as sources of variation. The random effect of animal was used to test diet, breed, and DIM, whereas the effects of period were tested on the residual. Breed had a small influence on milk FA profile, mainly on branched- and odd-chain FA. Within breed, animal repeatability for the relative proportions of milk FA was notable for almost all monounsaturated FA and for saturated FA with 14 to 19 carbon atoms, except C16:0, and less so for polyunsaturated FA. The inclusion of rpCLA (CLA cis-9,trans-11 and CLA trans-10,cis-12) increased the presence of the same CLA isomers in the milk as well
\end{abstract}

Received May 21, 2014.

Accepted December 13, 2014

${ }^{1}$ Corresponding author: franco.tagliapietra@unipd.it as that of CLA trans-9,trans-11, and decreased the proportions of de novo-synthesized short-chain FA. From a cluster analysis based on the matrix of correlation coefficients among all FA relative proportions, 3 main FA groups were observed: the first included mainly odd- or branched-chain saturated FA, C18:0, C16:0 and CLA trans-10, cis-12; the second included monounsaturated FA or polyunsaturated FA with 16 to 20 carbons, CLA cis-9,trans-11, and CLA trans-9,trans-11; and the third included short- to medium-chain saturated FA, polyunsaturated FA with 2 to 5 double bonds, and 3 CLA isomers not affected by rpCLA addition (CLA trans11,cis-13, CLA cis-9,cis-11, and CLA cis-10,cis-12).

Key words: conjugated linoleic acid (CLA), ovine milk, fatty acid, sheep breed, 2-dimensional gas chromatography

\section{INTRODUCTION}

Compared with bovine products, ovine products are known for their greater content of some FA that are considered beneficial for human health (Wahle et al., 2004; Sinclair, 2007), such as PUFA including linolenic acid, n-3 PUFA, and isomers of CLA (Dilzer and Park, 2012; Shingfield et al., 2013). Sheep milk is seldom consumed as a fresh product, so these effects would be exploited by the consumption of processed milk (Prandini et al., 2007), especially cheese (Nudda et al., 2005; Buccioni et al., 2010). In the case of bovine milk, the recovery of the majority of PUFA and CLA from milk to ripened cheese is thought to be greater than $80 \%$ (Cattani et al., 2014).

The FA profile of ovine milk depends partly on the genetic and physiological characteristics of the ovine breeds but also from feeding system (Pulina et al., 2006; De La Fuente et al., 2009). Milk obtained from animals kept on grass-based diets is commonly richer in these FA compared with that obtained from animals kept on hay-, silage- or concentrate-based diets (Jutzeler van Wijlen and Colombani, 2010). The increased use indoor of corn silage and concentrates and the abandonment of seasonality in favor of continuous production sys- 
tems are factors that would impair the quality of the lipid component of sheep milk. Nevertheless, the use of some rumen-protected fat can be a useful tool to deliver beneficial FA in tissues and milk. The use of rumenprotected CLA (rpCLA) supplements, containing the 2 most promising CLA isomers, C18:2 cis-(c)9, trans$(\boldsymbol{t}) 11$ and $\mathrm{C} 18: 2 \mathrm{t} 10, c 12$, has been found to be effective in modifying the FA profile of both beef meat (Schiavon et al., 2011) and cow's milk (Pappritz et al., 2011). Less is known about influencing the FA profile of sheep milk (Weerasinghe et al., 2012) and lamb (Mir et al., 2000; Terré et al., 2011) tissues through supplementation of CLA on indoor diets based on corn silage and concentrate-based diets. We hypothesize that administration of rpCLA could be an effective means to increase the CLA content of milk sheep, and a way to modify the presence of other FA because of possible interferences with the lipid metabolism.

The availability of powerful analytical methodology and equipment, such as 2-dimensional gas-chromatography $(\mathbf{G C} \times \mathbf{G C})$, makes a detailed assessment of the FA profile feasible (Manzano et al., 2011), improving our ability to study the influence of different source of variations, even for molecules present in small amounts but that could exert important biochemical functions. A basic characteristic of the $\mathrm{GC} \times \mathrm{GC}$ technique is the 2 -dimensional ordered structure of the chromatogram, which makes identification of compounds more reliable than in traditional GC (Adahchour et al., 2008). This technique would be useful for the analysis of samples where compounds are present in very different concentrations across a wide range of different FA (Vlaeminck et al., 2007).

The aim of this research was to study the effects of diet supplementation with a rumen-protected mixture of 2 CLA isomers (CLA $c 9, t 11$, CLA $t 10, c 12$ ) on a detailed FA profile. In particular, our objective was to quantify the increase of these 2 CLA isomers in milk fat, to analyze possible effects on other CLA isomers, and to test the hypothesis that CLA addition can modify lipid metabolism and particularly the de novo synthesis of FA in the mammary gland. An additional objective was to study the effect of animal source of variation of the detailed FA profile of milk collected from ewes of 3 autochthonous breeds (Brogna, Foza, and Lamon) of the Veneto Alps, using the $\mathrm{GC} \times \mathrm{GC}$ technique.

\section{MATERIALS AND METHODS}

\section{Animals, Feeding, and Milk Sampling}

This experiment was carried out at the "Lucio Toniolo" Experimental Farm of the University of Padova in Legnaro (Padova, Italy) on animals undergoing an in situ conservation program of the sheep breeds autochthonous of the Alpine areas of the Veneto region (northeast Italy). Animals were treated according to the Guidelines for the Care and Use of Agricultural Animals in Agricultural Research and Teaching (FASS, 1988).

Twenty-four ewes with their 31 suckling lambs, of Brogna (10 ewes), Foza (9 ewes), and Lamon (5 ewes) breeds, were allotted in 6 pens $(3 \times 6 \mathrm{~m}$ each $)$ of an open barn ( 2 pens/breed), homogeneous for DIM ( $38 \pm$ $23 \mathrm{~d})$ and ewe BW $(61 \pm 13 \mathrm{~kg})$. The 12 ewes of 3 pens (1 pen/breed) were fed a control diet, and the 12 ewes of the other 3 pens received the same diet top dressed and mixed with $12 \mathrm{~g} / \mathrm{d}$ per ewe, plus $4 \mathrm{~g} / \mathrm{d}$ for each lamb older than $30 \mathrm{~d}$, of a commercial rpCLA supplement (SILA, Noale, Italy) that contained, as detailed in Schiavon et al. (2010), 79.2 and $76.8 \mathrm{~g} / \mathrm{kg}$ of C18:2 $c 9, t 11$ and $\mathrm{C} 18: 2 t 10, c 12$ isomers, respectively.

The experimental conditions and the composition of diets were described in detail by Bittante et al. (2014). Briefly, the control diet was composed of $37.3,26.0$, $11.1,11.0,6.4,6.6$, and $1.6 \%$ DM corn grain, corn silage, dried sugar beet pulp, soybean meal, wheat bran, wheat straw, and a vitamin mineral mixture, respectively. From chemical analysis performed on each feed ingredient and from ingredient compositions, the diet contained 13.0, 29.3, 14.6, and $34.7 \% \mathrm{DM}$ of $\mathrm{CP}$, $\mathrm{NDF}, \mathrm{ADF}$, and starch, respectively, and $11.4 \mathrm{MJ} / \mathrm{kg}$ of DM of ME (Bittante et al., 2014). Diet ingredients were mixed with water to reach an average dietary DM content of $50.4 \%$ and offered ad libitum as TMR. The amount of each feed ingredient loaded into the mixer wagon, and the weight of the mixture uploaded in the manger of each pen was recorded daily. The orts remaining in the mangers were weighed weekly by pen. The study lasted $63 \mathrm{~d}$. At the beginning and end of the trial and every $2 \mathrm{wk}$, the ewes and their offspring were individually weighed and scored for BCS by a single trained technician.

Six times during the experiment, in the morning, the ewes were separated from their offspring for $2 \mathrm{~h}$, and milk samples were collected from each ewe, refrigerated, and analyzed for fat, protein, and lactose contents using a MilkoScan FT2 (Foss, Hillerød, Denmark) according to Bittante et al. (2014). For the purposes of current work, an aliquot of each milk sample was conserved at $-80^{\circ} \mathrm{C}$. Prior to analysis, milk samples were thawed and pooled in 2 composite samples for each ewe: the first pooled the 3 milk samples collected during the first month of the trial (period A) and the second pooled the 3 samples collected during the second month of the trial (period B). 


\section{Lipid Extraction and FA Methylation}

The lipid extraction procedure was performed according to Hara and Radin (1978) and Chouinard et al. (1999) using as a solvent hexane:isopropanol (3:2, vol/ vol) solution at room temperature. Fresh milk samples were mixed and homogenized, and $5 \mathrm{~mL}$ was poured into a round-bottomed flask (Duran Group GmbH, Mainz, Germany). Samples were blended 3 times with hexane:isopropanol $(3: 2, \mathrm{vol} / \mathrm{vol})$. The washes were made with $7.5 \mathrm{~mL}$ of hexane and $10 \mathrm{~mL}$ of isopropanol, and the solution was allowed to rest for $1 \mathrm{~h}$ to allow the phases to separate. In each of the 3 washing steps after resting, the 2 phases were separated, and the lipid isopropanol phase was transferred into another roundbottomed flask, blended by adding a saline solution (0.47 $\mathrm{M} \mathrm{Na}_{2} \mathrm{SO}_{4}, 5 \mathrm{~mL} / \mathrm{g}$ ) to permit the separation of the upper hexane-water phase from the lipid isopropanol phase. The final isopropanol solution was collected and transferred into a flat-bottomed flask and heated at $35^{\circ} \mathrm{C}$ under $\mathrm{N}_{2}$ stream for about $20 \mathrm{~min}$ to complete solvent evaporation, and the resulting extracted fat material was weighed. About $44 \mathrm{mg}$ of fat was transferred into culture tubes to be immediately methylated according to Christie (2001) using $1 \mathrm{M}$ sodium methoxide in methanol at room temperature. Two milliliters of $n$-hexane, containing $2 \mathrm{mg} / \mathrm{mL}$ of methyl 12-tridecenoate as internal standard (\#U-35 M, Nu-Chek Prep Inc., Elysian, MN), and $100 \mu \mathrm{L}$ of $1 M$ sodium methoxide in methanol were added to the extracted fat. The solution containing the extracted fat and the solvent was mixed for 10 min using a multi mixer $(717+$, ASAL s.r.l., Florence, Italy) at room temperature. After this step, $150 \mu \mathrm{L}$ of oxalic acid in ethyl ether was added to stop the reaction in the solution containing FAME. The solution was agitated for $30 \mathrm{~s}$ and centrifuged at $8,000 \times g$ for $10 \mathrm{~min}$ at $4^{\circ} \mathrm{C}$ (Sigma Laborzentrifugen 3K15, Osterode am Harz, Germany). The upper phase was taken $(1 \mathrm{~mL})$ and transferred to a vial for the GC $\times$ GC analysis.

\section{GC Analysis}

The samples obtained were analyzed for FA profile using a GC $\times$ GC instrument (Agilent 7890A, Agilent Technologies, Santa Clara, CA) with 2 columns in series, equipped with a modulator (Agilent G3486A CFT), an automatic sampler (Agilent 7693) and a flame-ionization detector connected to a chromatography data system software (Agilent Chem Station). This instrument was used because the use of a double column allows much better separation and identification of FA, especially of CLA isomers, on a 2-dimensional basis, compared with the traditional one-column
GC (Cesaro et al., 2013). Between the 2 columns, a modulator unit collects, in a fixed volume channel, the analyte bands of the first column and these are successively launched into the short second column in narrow bands. The operative conditions of the GC apparatus were as follows: (1) first column of $75 \mathrm{~m} \times 180 \mu \mathrm{m}$ (internal diameter $) \times 0.14 \mu \mathrm{m}$ film thickness $(23348 \mathrm{U}$, Supelco, Bellefonte, PA), $\mathrm{H}_{2}$ carrier flow of $0.22 \mathrm{~mL} /$ min; (2) second column of $3.8 \mathrm{~m} \times 250 \mu \mathrm{m}$ (internal diameter $) \times 0.25 \mu \mathrm{m}$ film thickness (J\&W 19091-L431, Agilent Technologies), $\mathrm{H}_{2}$ carrier flow of $22 \mathrm{~mL} / \mathrm{min}$; (3) planned oven temperature variation: increased from $50^{\circ} \mathrm{C}$ (held for $2 \mathrm{~min}$ ), increased to $150^{\circ} \mathrm{C}$ (held for 15 $\min$ ) at $50^{\circ} \mathrm{C} / \mathrm{min}$, and then increased to $240^{\circ} \mathrm{C}$ (held for $84 \mathrm{~min}$ ) at $2^{\circ} \mathrm{C} / \mathrm{min}$; (4) valves: modulation delay, $1.00 \mathrm{~min}$; modulation period, $2.90 \mathrm{~s}$; sample time, 2.77 $\mathrm{s}$; (5) flame-ionization detector: heater, $250^{\circ} \mathrm{C}, \mathrm{H}_{2}$ carrier flow $20 \mathrm{~mL} / \mathrm{min}$, air flow $450 \mathrm{~mL} / \mathrm{min}$; (6) splitless inlet: temperature $270^{\circ} \mathrm{C}$, pressure $20.698 \mathrm{MPa}$, septum purge $3 \mathrm{~mL} / \mathrm{min}$, split ratio $20 \mathrm{~mL} / \mathrm{min}$.

The resulting 2-dimensional chromatograms were analyzed with the comprehensive GC $\times$ GC software (Zoex Corp., Houston, TX) to evaluate the cone volume of each FA.

\section{Identification and Quantification of FA}

Identification of FA was completed in 2 ways; the first was by comparison of the cone position in the chromatogram with the cone position of FA contained in the GC reference standards. The reference standards used were mixtures of pure FA [\#674, \#463 (NuChek Prep Inc.), 47080-U bacterial acid methyl esters (Sigma-Aldrich, St. Louis, MO), 47085-U PUFA-3 menhaden oil (Supelco)] plus individual CLA isomers [CLA $c 9, t 11$ (\#UC-60M, Nu-Chek Prep Inc.), CLA t10,c12 (\#UC-61M, Nu-Chek Prep Inc.), CLA $c 9, c 11$ (\#1256, Matreya LLC, Pleasant Gap, PA), CLA t9, $t 11$ (\#1257, Matreya LLC), and CLA $c 11, t 13$ (\#1259, Matreya LLC)]. The second FA identification procedure was completed by considering the elution order and position of each cone in the 2-dimensional chromatogram based on comprehensive GC $\times$ GC software $(\mathrm{GC}$ Imagine Software, Zoex Corp.). In the region of the C18:1 isomers were detected different peaks and 2 of them, C18:1 t9 (elaidic acid) and C18:1 t11 (vaccenic acid), were partially co-eluted. Quantification of each FA was made considering the cone volume of each FA peak with respect to the volume of total FA and was expressed in terms of grams of FA per grams of total FA $\times 100$, based on the concentration in weight of the methyl 12-tridecenoate contained in the solution used as internal standard. The various FA were summed in the following categories: 
$\mathrm{SFA}=$ sum of C4:0, C6:0, C7:0, C8:0, C9:0 C10:0, $\mathrm{C} 11: 0, \mathrm{C} 11: 0$ iso, C12:0, C12:0 iso, C13:0, C13:0 iso, $\mathrm{C} 13: 0$ anteiso, C14:0, C14:0 iso, C14:0 anteiso, C15:0, $\mathrm{C} 15: 0$ iso, C15:0 anteiso, C16:0, C16:0 iso, C16:0 anteiso, C17:0, C17:0 iso, C17:0 anteiso, C18:0, C18:0 iso, $\mathrm{C} 18: 0$ anteiso, C19:0, C19:0 iso, C19:0 anteiso, C20:0, C21:0, C22:0, C23:0, and C24:0.

MUFA $=$ sum of $\mathrm{C} 10: 1, \mathrm{C} 11: 1, \mathrm{C} 12: 1, \mathrm{C} 12: 1 t$, $\mathrm{C} 12: 1 c, \Sigma \mathrm{C} 13: 1_{\text {others }}, \mathrm{C} 14: 1 \quad c 9, \mathrm{C} 14: 1$ t9, $\Sigma \mathrm{C} 14: 1_{\text {others }}$, C15:1, C15:1 $t, \Sigma \mathrm{C} 15: 1_{\text {others }}, \mathrm{C} 16: 1$ t7, C16:1 c7, C16:1 $c 9, \quad \Sigma \mathrm{C} 16: 1_{\text {others }}, \mathrm{C} 17: 1 \quad c 10, \mathrm{C} 17: 1 \quad t, \quad \Sigma \mathrm{C} 17: 1_{\text {others }}$, C18:1 t9 (+t11), C18:1 $c 9, \quad \mathrm{C} 18: 1 \quad c 7, \quad \mathrm{C} 18: 1 \quad t 12$, C18:1 $c 12, \quad \Sigma \mathrm{C} 18: 1_{\text {others }}, \mathrm{C} 19: 1, \mathrm{C} 19: 1 \quad c, \mathrm{C} 19: 1 \quad c 9$,

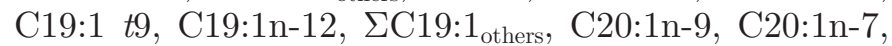
$\Sigma \mathrm{C} 20: 1_{\text {others }}, \Sigma \mathrm{C} 21: 1_{\text {others }}, \Sigma \mathrm{C} 22: 1_{\text {others }}$, and C24:1.

$\mathrm{PUFA}=$ sum of $\Sigma \mathrm{C} 16: 2_{\text {others }}, \Sigma \mathrm{C} 17: 2_{\text {others }}, \mathrm{C} 18: 2 \mathrm{n}-6$, $\Sigma \mathrm{C} 18: 2_{\text {others }}, \quad \Sigma \mathrm{C} 19: 2_{\text {others }}, \quad \mathrm{C} 20: 2 \mathrm{n}-6, \quad \mathrm{C} 20: 2 \mathrm{n}-3$, $\Sigma \mathrm{C} 20: 2_{\text {others }}, \Sigma \mathrm{C} 16: 3_{\text {others }}, \mathrm{C} 18: 3 \mathrm{n}-3, \mathrm{C} 18: 3 \mathrm{n}-6, \mathrm{C} 20: 3 \mathrm{n}-3$, C20:3n- $6, \Sigma \mathrm{C} 20: 3_{\text {others }}, \Sigma \mathrm{C} 16: 4_{\text {others }}, \mathrm{C} 18: 4 \mathrm{n}-1, \mathrm{C} 18: 4 \mathrm{n}-3$, C18:4n-4 C20:4n-3, C20:4n-6, $\Sigma$ C20:4 $4_{\text {others }}, \mathrm{C} 18: 5 n-3$, C20:5n-3, C20:5n-6, $\Sigma$ C20:5 $5_{\text {others }}$, C22:4n-6, C22:5n-3, C22:5n-6, C22:6n-3, CLA $c 9, t 11$, CLA $t 10, c 12$, CLA $c 11, t 13$, CLA $t 9, t 11$, CLA $c 9, c 11$, and CLA $c 10, c 12$.

Branched-chain fatty acids were calculated according to Raes et al. (2004) and were the sum of C13:0 iso, C13:0 anteiso, C14:0 iso, C14:0 anteiso, C15:0 iso, $\mathrm{C} 15: 0$ anteiso, $\mathrm{C} 16: 0$ iso, $\mathrm{C} 16: 0$ anteiso, $\mathrm{C} 17: 0$ iso, $\mathrm{C} 17: 0$ anteiso, $\mathrm{C} 18: 0$ iso, $\mathrm{C} 18: 0$ anteiso, $\mathrm{C} 19: 0$ iso, and C19:0 anteiso. Odd-chain fatty acids were calculated according to Or-Rashid et al. (2007). The sum of the identified CLA isomers $(\boldsymbol{\Sigma C L A})$ was calculated as the sum of CLA $c 9, t 11$ CLA $t 10, c 12$, CLA $t 11, c 13$, CLA $c 9, c 11$, CLA $c 10, c 12$, and CLA $t 9, t 11$. The sum of n-3 PUFA or n-6 PUFA were calculated according to Connor (2000); for example, n-3 PUFA was computed as the sum of C18:3n-3, C18:4n-3 C18:5n-3, C20:2n-3, C20:3n-3, C20:4n-3, C20:5n-3 (eicosapentaenoic acid), C22:5n-3, C22:6n-3 (docosahexaenoic acid).

The $\Delta^{9}$-desaturase indices were calculated, according to Kelsey et al. (2003), for 4 pairs of FA that represent products and substrates for $\Delta^{9}$-desaturase. These FA pairs were 14:1 $c 9 / 14: 0,16: 1 c 9 / 16: 0,18: 1 c 9 / 18: 0$, and $\mathrm{C} 18: 2 c 9, t 11 / \mathrm{C} 18: 1 t 11$. We defined the total desaturase index as follows: [products of $\Delta^{9}$-desaturase]/[products of $\Delta^{9}$-desaturase + substrates of $\Delta^{9}$-desaturase];

The atherogenic index (AI) and thrombogenic index (TI) were calculated according to Ulbricht and Southgate $(1991)$ as follows: $\mathrm{AI}=(\mathrm{C} 12: 0+4 \times \mathrm{C} 14: 0+$ C16:0)/(n-3PUFA + n-6PUFA + MUFA $) ;$ and $\mathrm{TI}=$ $(\mathrm{C} 14: 0+\mathrm{C} 16: 0+\mathrm{C} 18: 0) /(0.5 \times \mathrm{MUFA}+0.5 \times \mathrm{n}-$ 6 PUFA $+3 \times$ n-3 PUFA $/$ n-6PUFA $)$.

\section{Statistical Analysis}

Fatty acid proportions $(\mathrm{g} / \mathrm{g}$ of total FA $\times 100)$ of milk samples were analyzed using the MIXED procedure of SAS (version 8.2, SAS Institute Inc., Cary, NC). Data were analyzed with a linear mixed model considering the effect of the diet (control vs. CLA), breed (Brogna, Foza, and Lamon), number of suckling lambs (single vs. twins), linear covariate of DIM at the beginning of the trial, and period of sampling (period A vs. B) as fixed effects. The random effect of animal (24 ewes, $18 \mathrm{df}$ ) was used to test diet, breed, and number of suckling lambs and DIM, whereas the effects of period of sampling was tested on the residual. From a preliminary analysis, the number of suckling lambs was never significant for FA profile, with the exception of C17:0 anteiso, and this factor was omitted from the model. The following orthogonal contrasts were computed: Brogna versus (Foza+Lamon); that is, the mid-sized dairy breed versus the average of the 2 large meaty breeds, and Foza versus Lamon breed. Data on milk composition were analyzed using the same model but with substitution of the 2 periods with 5 sampling dates. Data regarding ewe and lamb BW, growth rate, and BCS variation (1 observation per animal) were analyzed using a linear model similar to that used for FA profile, but without the effect of period and the random effect of animal. Pearson's product-moment correlations among the proportion of all individual FA were calculated and then the correlation matrix was subsequently fed to the R function "hclust" (R Development Core Team, 2009) for clustering purposes. The "hclust" function in R uses the complete linkage method for hierarchical clustering as detailed in Maechler et al. (2012).

\section{RESULTS}

Results on major milk constituents, as well as on cheese-making properties, were reported in Bittante et al. (2014), and some of these are summarized in Figure 1. The rpCLA supplementation decreased milk protein content compared with the control diet. The rpCLAsupplemented ewes produced milk with $10 \%$ less fat and total FA that those receiving the control diet, but the difference was not significant because the residual variation observed for this trait was high. Supplementation with rpCLA had no effect on BW, ADG, or BCS variation of ewes and their suckling lambs (Table 1). Ewe DMI averaged 2.67 and $2.63 \mathrm{~kg} / \mathrm{d}$ for the control and the rpCLA treatments, respectively. 


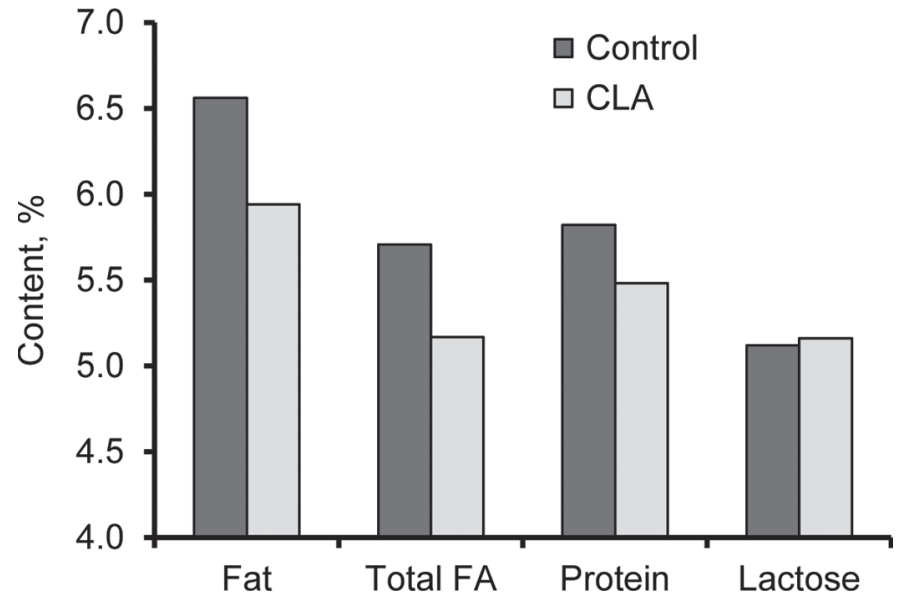

Figure 1. Effect of rumen-protected CLA supply on fat $[P=0.41$; root mean square error $(\mathrm{RMSE})=2 \%]$, total fatty acid $(\mathrm{FA} ; P=0.39$; RMSE $1.8 \%)$, protein $(P=0.02 ;$ RMSE $=0.07 \%)$, and lactose $(P=$ 0.77 ; RSE $=0.04 \%)$ contents in milk of ewes from 3 native breeds of the Veneto Alps.

\section{Two-Dimensional GC}

The GC $\times$ GC system revealed the presence in milk of 170 cones corresponding to 33 SFA, 53 MUFA, 76 PUFA, and 8 unidentified FA. For reasons of space, FA partially identified were summed in groups according to the length of their carbon chain and degree of unsaturation. In total, 29 SFA, 17 MUFA, and 5 sums of other MUFA, 9 PUFA and 3 sums of other PUFA, and 6 CLA isomers are presented in the tables. Three main groups of milk FA were distinguished by the cluster analysis conducted in this work (Figure 2). The first group, regarded in large majority odd- or branched-chain (iso or anteiso) SFA, but also C18:0, C16:0, and CLA t10,c12. The second group was represented by MUFA or PUFA with 16 to 20 carbons, CLA $c 9, t 11$, and CLA t9, $t 11$. The third group, the most heterogeneous, was represented by short-to medium-chain SFA, PUFA with 2 to 5 double bounds, CLA t11,c13, and 2 other cis,cis CLA isomers.

\section{Breed and Animal Within Breed Variation}

Differences in milk SFA profile due to breed were rare (Table 2). Milk from Foza and Lamon (large meaty breeds) compared with that of Brogna (medium-size multipurpose breed) differed only for some iso forms and odd-numbered SFA: a lesser content of C15:0 iso, a tendency for lesser contents of both C17:0 iso and C17:0 anteiso, and a greater content of C19:0. Milk from Foza ewes contained a greater proportion of iso forms of C13:0, C14:0, C15:0, and C16:0 compared with that from Lamon ewes. The relative incidence of animal within breed variance on the sum of residual plus animal variance, an index of animal repeatability, showed large variation among FA (Table 2). For even-numbered FA, this index was low or null for C4:0, C10:0, C20:0, and C22:0, and moderate for other FA of the same category, ranging from 0.15 to 0.30 for C6:0 and C14:0, respectively. For odd-numbered notbranched SFA, this index was small or null for shortchain FA up to C13:0 (on average 0.10), large for C15:0

Table 1. Effect of rumen-protected CLA supplementation on BW, average daily gain (ADG), BCS ${ }^{1}$ variation, and DMI of ewes and suckling lambs belonging to 3 native breeds of the Veneto Alps

\begin{tabular}{|c|c|c|c|c|}
\hline \multirow[b]{2}{*}{ Item } & \multicolumn{2}{|c|}{ Diet $^{2}$} & \multirow[b]{2}{*}{$P$-value } & \multirow[b]{2}{*}{$\mathrm{RMSE}^{3}$} \\
\hline & Control & CLA & & \\
\hline \multicolumn{5}{|l|}{ Ewes } \\
\hline Initial BW, $\mathrm{kg}$ & 64.2 & 61.1 & 0.57 & 11.8 \\
\hline Final BW, kg & 65.4 & 63.5 & 0.72 & 11.6 \\
\hline $\mathrm{ADG}, \mathrm{g} / \mathrm{d}$ & 40 & 20 & 0.44 & 56 \\
\hline Initial BCS & 2.77 & 2.78 & 0.94 & 0.28 \\
\hline Final BCS & 3.16 & 3.03 & 0.38 & 0.33 \\
\hline Change in BCS & 0.39 & 0.25 & 0.25 & 0.25 \\
\hline \multicolumn{5}{|l|}{ Lambs } \\
\hline Initial BW, $\mathrm{kg}$ & 12.9 & 13.7 & 0.51 & 3.0 \\
\hline Final BW, kg & 20.9 & 21.5 & 0.72 & 4.0 \\
\hline $\mathrm{ADG}, \mathrm{g} / \mathrm{d}$ & 134 & 130 & 0.76 & 33 \\
\hline Initial BCS, kg & 3.01 & 3.16 & 0.14 & 0.23 \\
\hline Final BCS, kg & 3.22 & 3.27 & 0.70 & 0.28 \\
\hline Change in BCS & 0.21 & 0.11 & 0.10 & 0.15 \\
\hline
\end{tabular}

${ }^{1}$ Score according to a scale from 1 (emaciated) to 5 (obese).

${ }^{2}$ Each data are the least squares means of 3 pen data, with 12 ewes and their offspring/diet. The rumenprotected CLA diet differed from the control only for the supply, by top dressing, of $12 \mathrm{~g} / \mathrm{d}$ per ewe plus $4 \mathrm{~g} / \mathrm{d}$ for each lamb older than $30 \mathrm{~d}$ of a commercial CLA mixture (SILA, Noale, Italy).

${ }^{3}$ Root mean square error. 


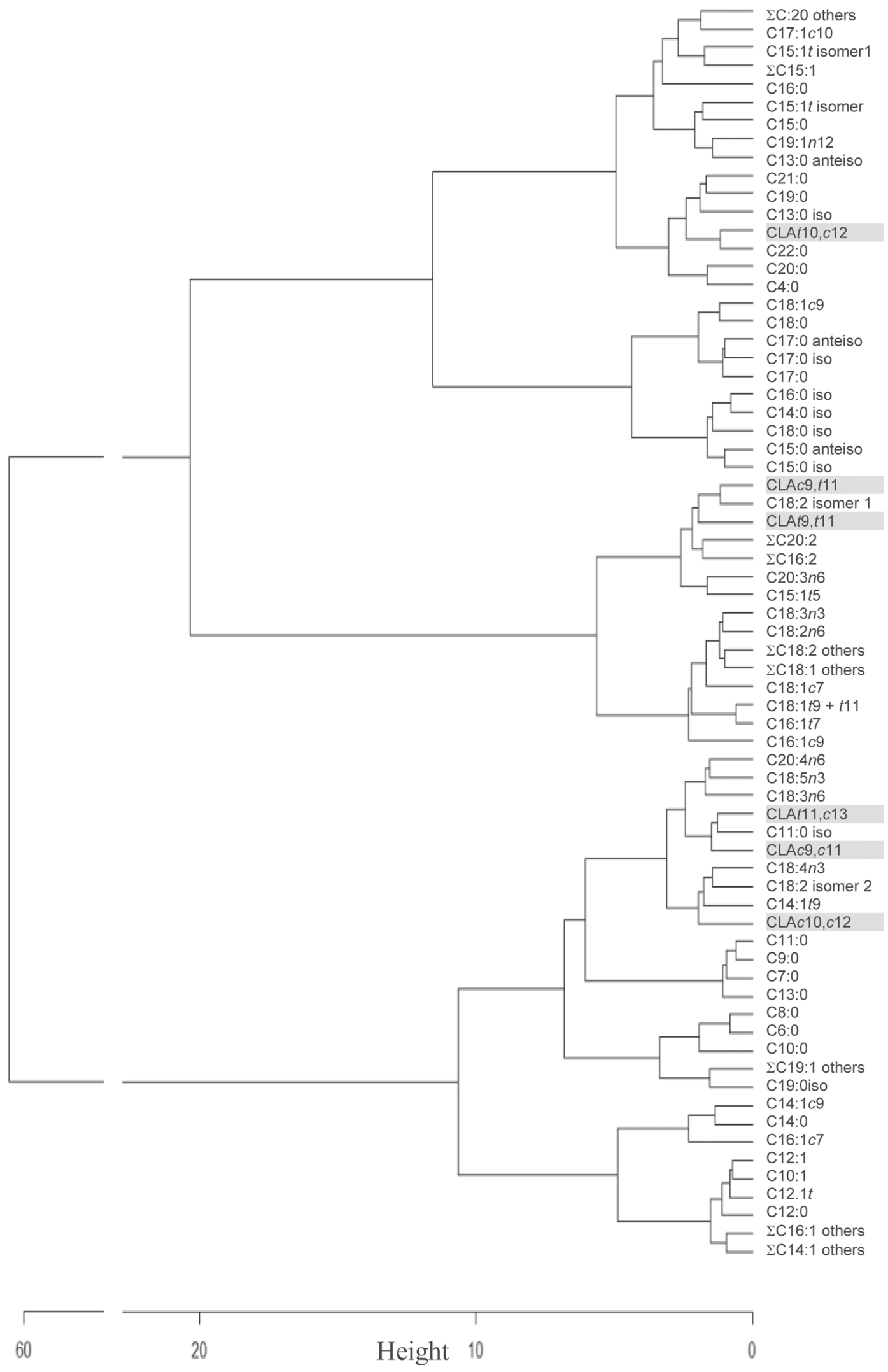

Figure 2. Hierarchical clustering of phenotypic correlations among the proportion of all individual FA $(\mathrm{g} / \mathrm{g}$ of total FA $\times 100) . t=t r a n s ;$ $c=$ cis. 
Table 2. Effects of breed and of animal within breed on the proportion of milk SFA (g/100 g FA) of 3 native sheep breeds of the Veneto Alps (FA are listed in order of elution)

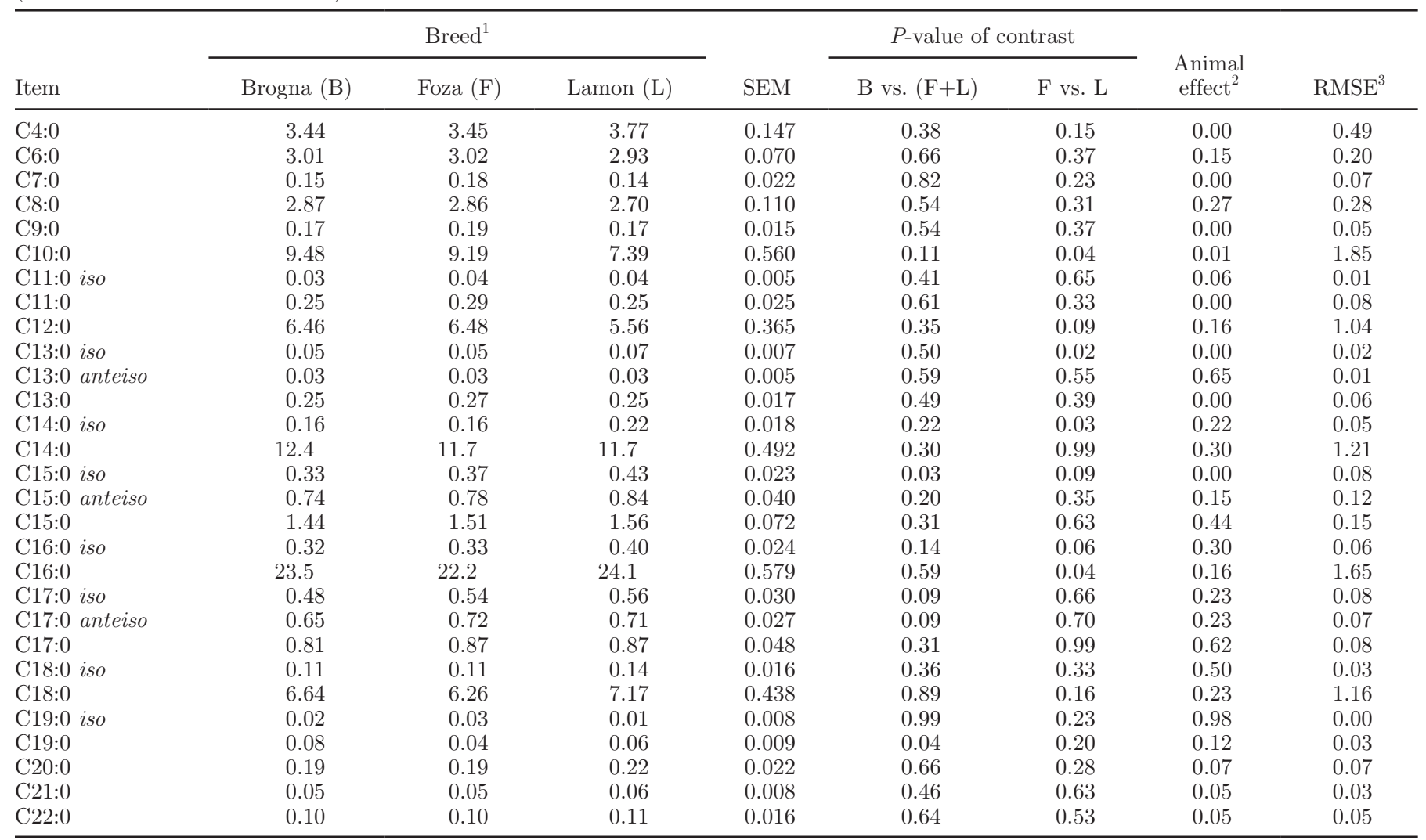

${ }^{1}$ Data are least squares means resulting from the following design: 3 breeds $\times 2$ diets $\times 2$ to 6 ewes $\times 2$ periods of milk sampling $\times 2$ analytical replications.

${ }^{2}$ Expressed as the ratio between the variance of animals within breed and the total variance (animal plus residual).

${ }^{3}$ Root mean square error.

(0.44) and C17:0 (0.62), and low for C19:0 (0.12) and C21:0 (0.05). For short-chain, branched SFA, animal repeatability was low $(\leq 0.22)$, with the exception of C13:0 anteiso (0.65), whereas for long-chain branched SFA, animal repeatability was $\geq 0.23$.

The effect of breed on the proportions of various MUFA and PUFA was also rare (Table 3). Milk from Brogna ewes differed from that of the other 2 breeds only for a smaller proportion of $\Sigma \mathrm{C} 19: 1_{\text {others }}$, not for C19:1n-12 or C18:2 $c 9, t 11$. Compared with milk obtained from Lamon ewes, the milk collected from Foza ewes had a smaller proportion of $\Sigma \mathrm{C} 19: 1_{\text {others }}$ and a greater proportion of $\mathrm{C} 12: 1, \mathrm{C} 14: 1$ t9, $\Sigma \mathrm{C} 20: 2_{\text {others }}$, C18:3n-6, CLA c11t13, and C18:4n-3.

Animal repeatability was medium to high for all MUFA and the value of this index was $\geq 0.30$, with only some exceptions with null values for $\Sigma \mathrm{C} 16: 1_{\text {others }}$ and $\mathrm{C} 17: 1 \mathrm{c} 10$, and moderate to low values for $\mathrm{C} 10: 1$ (0.22), C18:1 $c 9$ (0.13), C18:1 $c 7(0.23)$, and for the 2 C19:1 groups. In contrast, animal repeatability for the various PUFA was always $<0.30$, and often null, with exceptions for C18:2n-6 (0.49), CLA $t 10, c 12$ (0.39), and C20:4n-6 (0.37).

In terms of FA categories and indices (Table 4), the milk produced by Brogna tended to present smaller proportions of PUFA, $\Sigma$ CLA, and branched-chain FA compared with the other breeds, and Foza ewes produced milk with smaller proportions of medium-chain FA (C16) compared with the Lamon ewes. Animal repeatability was moderate to high $(0.15$ to 0.48$)$ for all FA categories and indices considered, except for the sums of unknown FA and for the ratio n-6:n-3 that showed null values.

\section{Rumen-Protected CLA Supply and Sampling Period}

The rpCLA supply increased the proportion of C4:0, decreased that of all other SFA with chains ranging 6 to 13 carbons, excluding the branched-chain FA, tended to increase that of $\mathrm{C} 20: 0$, and increased that of $\mathrm{C} 22: 0$ (Table 5). Initial stage of lactation had a small effect on SFA proportions, but a decrease in proportions of 
Table 3. Effects of breed and of animal within breed on the proportion of milk MUFA and PUFA ( $\mathrm{g} / 100 \mathrm{~g}$ of FA) of 3 native sheep breeds of the Veneto Alps (FA are listed in order of elution) ${ }^{1}$

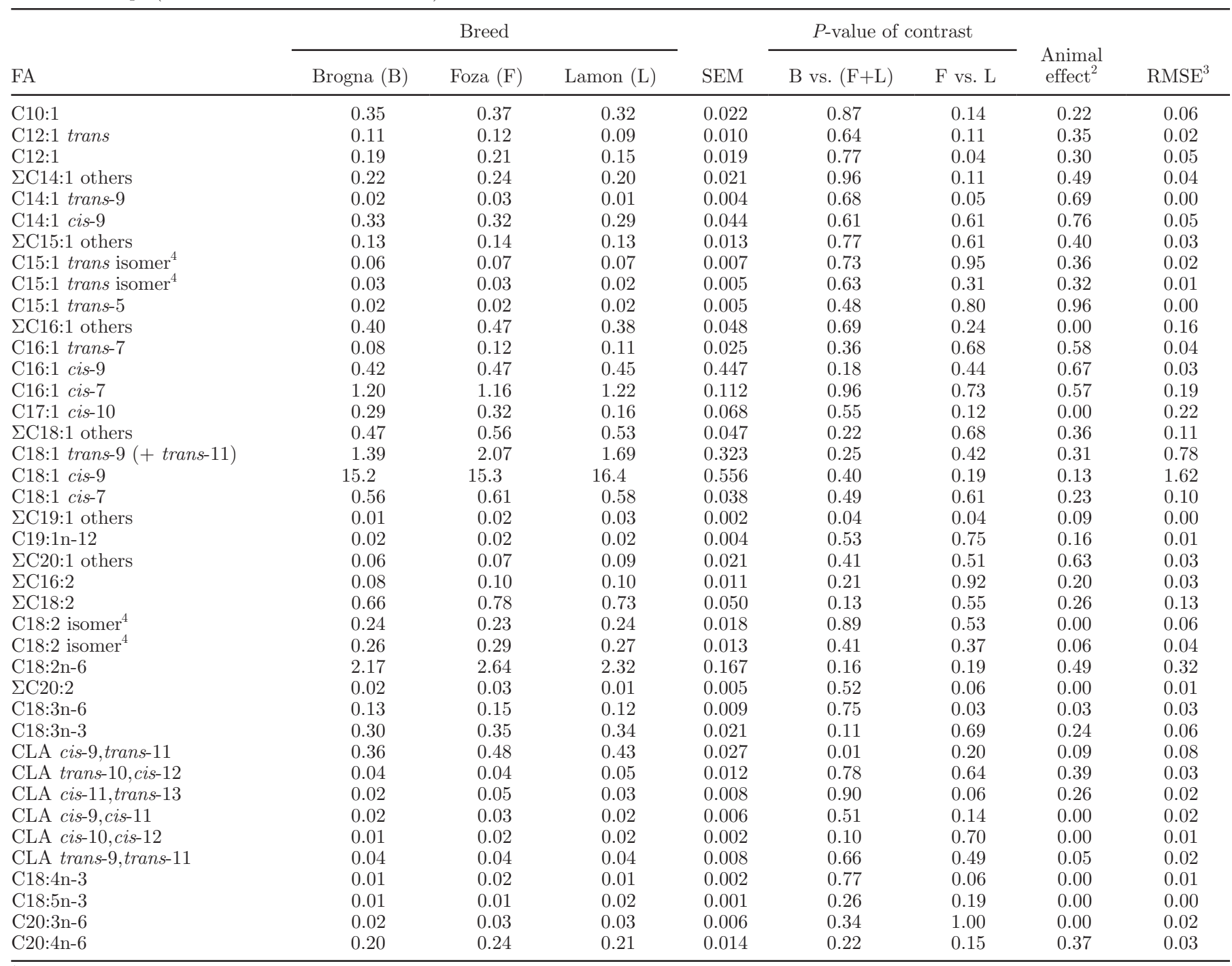

${ }^{1}$ Data are least squares means resulting from the following design: 3 breeds $\times 2$ diets $\times 2$ to 6 ewes $\times 2$ periods of milk sampling $\times 2$ analytical replications.

${ }^{2}$ Expressed as the ratio between the variance of animals within breed and the total variance (animal plus residual).

${ }^{3}$ Root mean square error.

${ }^{4}$ Isomers partially identified based on their ordered position in the 2-dimensional chromatograms.

C6:0, C8:0, and C18:0, and a tendency for an increase of C14:0 and C15:0 proportions was observed with increasing initial stage of lactation. Sampling period affected almost all SFA proportions: increased proportions of short-chain SFA (until C14:0) and decreased proportions of SFA with longer carbon chain were observed in the second period compared with the first.

The rpCLA supply also affected the proportion of several MUFA (Table 6), as it decreased or tended to decrease proportions of $\mathrm{C} 10: 1, \mathrm{C} 12: 1, \Sigma \mathrm{C} 16: 1_{\text {others }}$, and $\Sigma \mathrm{C} 20: 1_{\text {others }}$, and increased those of $\mathrm{C} 16: 1 \mathrm{t}, \mathrm{C} 18: 1 c 9$, and the sum of $\mathrm{C} 18: 1$ t9 and C18:1t11 (in the GC $\times$
GC chromatograms these last $2 \mathrm{FA}$ were co-eluted). In general, the rpCLA supply did not influenced the total proportion of PUFA, but increased the proportions of $\Sigma \mathrm{C} 16: 2_{\text {others }}$, the 2 CLA isomers supplied with the rumen-protected mixture (CLA $c 9, t 11$ and CLA $t 10, c 12$ ), and the cis-cis and trans-trans forms of isomers with double bonds in position 9 and 11 (CLA $c 10, c 12$ and CLA $t 10, t 12)$.

Similarly to the SFA, for MUFA and PUFA (Table 6 ), stage of lactation at the start of the trial had small effects, with some increases in the proportions of C12:1 $t, \Sigma \mathrm{C} 14: 1_{\text {others }}, \Sigma \mathrm{C} 16: 1_{\text {others }}, \mathrm{C} 16: 1 c 7, \mathrm{CLA} c 9, t 11$, and 
Table 4. Effects of breed and of animal on the proportion of categories of FA ( $\mathrm{g} / 100 \mathrm{~g}$ of FA) and on some indices of milk of 3 native sheep breeds of the Veneto Alps ${ }^{1}$

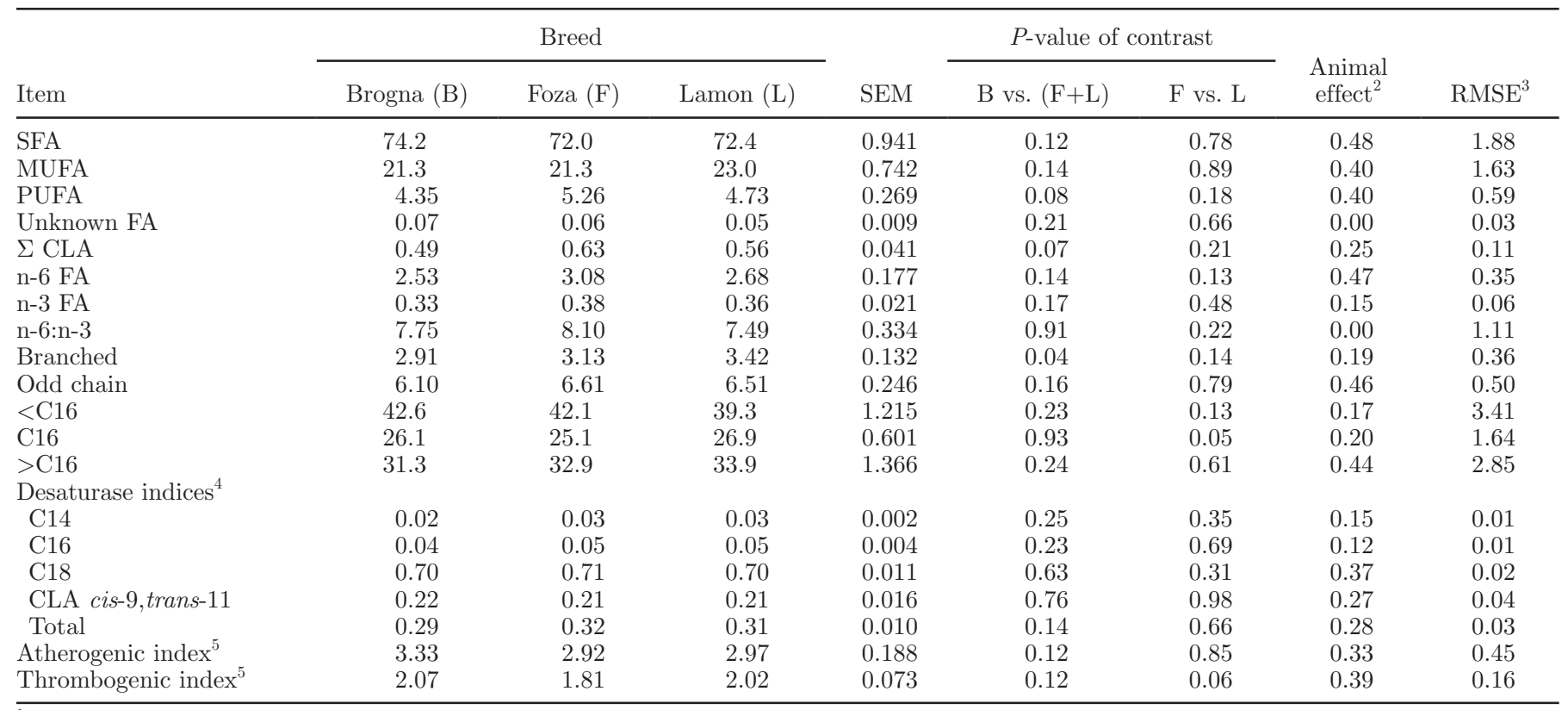

${ }^{1}$ Data are least squares means resulting from the following design: 3 breeds $\times 2$ diets $\times 2$ to 6 ewes $\times 2$ periods of milk sampling $\times 2$ analytical replications.

${ }^{2}$ Expressed as the ratio between the variance of the animals within breed and the total variance (animal plus residual).

${ }^{3}$ Root mean square error.

${ }^{4}$ Computed according to Kelsey et al. (2003).

${ }^{5}$ Computed according to Ulbricht and Southgate (1991).

CLA $c 9 c 11$. However, unlike for SFA, period of sampling affected most unsaturated FA. In this case, a notable decrease of $\mathrm{C} 18: 1 c 9$ from the first to second period was observed, which was compensated for by an increased proportion of the major part of other unsaturated FA.

Considering the FA categories given in Table 7, we observed that rpCLA supplementation decreased the proportions of SFA and short-chain FA and increased proportions of MUFA and long-chain FA and the sum of CLA isomers. Supplementation of rpCLA also increased the n-6:n-3 FA ratio, CLA $t 10, c 12$ desaturation index, and the total desaturation index. The initial stage of lactation affected only the n-6:n-3 FA ratio and C14 and C18 desaturation indices, but sampling period affected most FA categories and indices.

\section{DISCUSSION}

\section{Two-Dimensional GC}

The GC $\times$ GC technique offers high separation efficiency and enhanced sensitivity compared with singlecolumn GC (Manzano et al., 2011). A further characteristic of the $\mathrm{GC} \times \mathrm{GC}$ technique is the structured order of the chromatograms, which makes the identification of compounds more reliable than in traditional GC, particularly when columns with different polarity are used (Manzano et al., 2011). The GC $\times$ GC technique is also well suited for the analysis of samples in which compounds are present in very different concentrations (Cesaro et al., 2011). Compared with other biological samples, milk is a complex matrix with a great number of different FA originating from feed ingredients, rumen microbial activity, intestinal digestion, metabolic transformations, and mammary de novo synthesis. In the current work, the potential of this technique was highlighted by the 170 different FA detected, and by the ability to study the phenotypic relationships among them using the cluster analysis technique. In line with expectations, the results of current work suggest that the relative proportions of short-medium chain SFA (likely resulting from de novo synthesis occurring in the mammary gland) are negatively related to the proportions of odd FA, and of the iso and anteiso forms, the presence of which reflects rumen microbial activity. The various CLA isomers were not included in the same clustering groups, and their distances were notable (Figure 2). 
Table 5. Effects of rumen-protected CLA supplementation and sampling period on the proportion of milk SFA (g/100 g of FA) from 3 native sheep breeds of the Veneto Alps (FA are listed in order of elution)

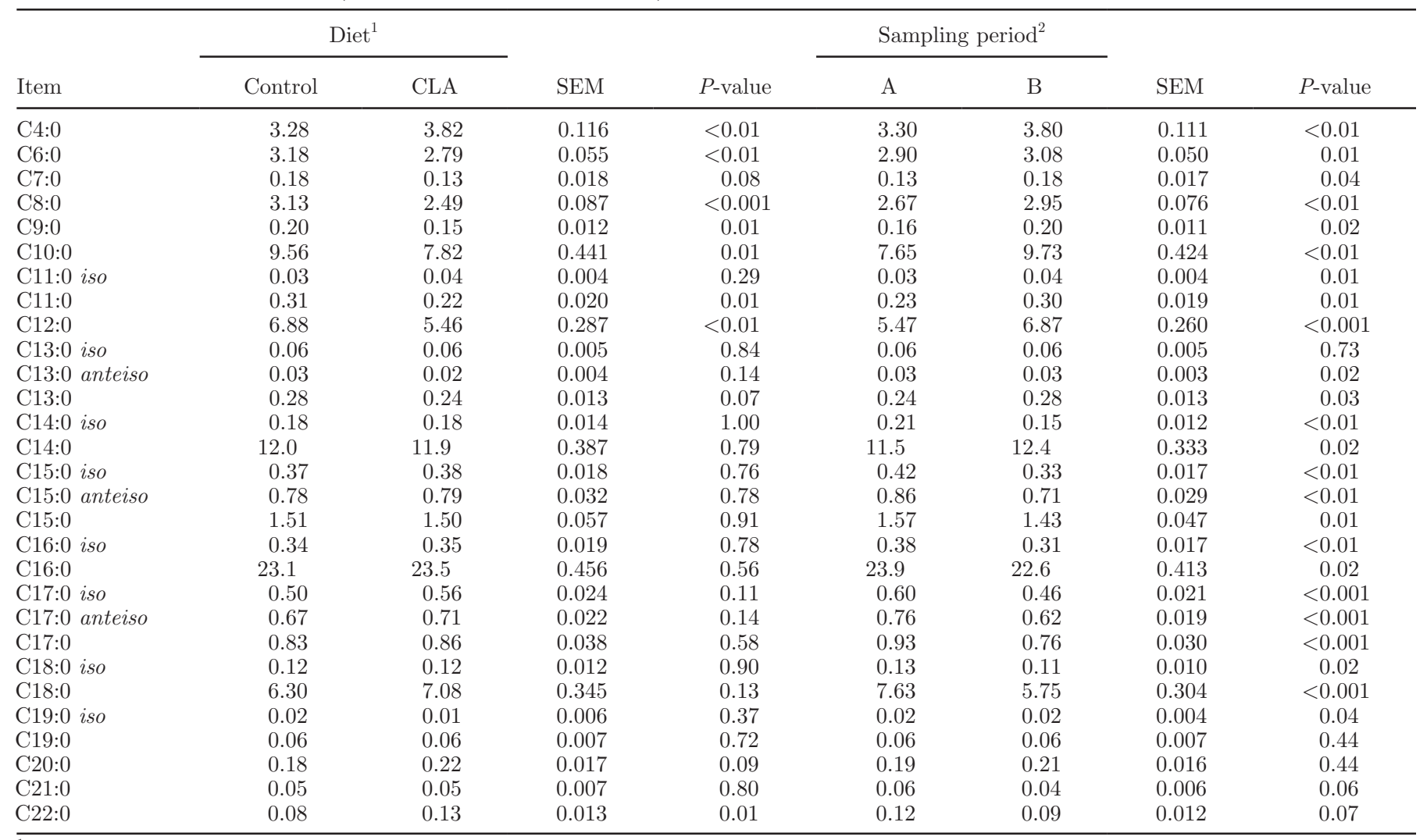

${ }^{1}$ Data are least squares means resulting from the following design: 3 breeds $\times 2$ diets $\times 2$ to 6 ewes $\times 2$ periods of milk sampling $\times 2$ analytical replications. The CLA diet was obtained by top dressing the control diet with $12 \mathrm{~g} / \mathrm{d}$ per ewe plus $4 \mathrm{~g} / \mathrm{d}$ for each lamb older than $30 \mathrm{~d}$ of a commercial CLA mixture (SILA, Noale, Italy).

${ }^{2}$ Periods A and B indicate milk samples collected during the first and second months of trial, respectively.

\section{Breed Effect}

Brogna, Foza, Lamon, and Alpagota are native breeds reared in the Veneto region with different morphological and production abilities (Pastore, 2002; Pellattiero et al., 2011). Brogna is represented by a few thousand sheep reared in the hills of Verona province and used for production of lambs and for milk to be processed to a local cheese called Pegorin. The Foza and Lamon breeds are used for lamb production, but they are currently in danger of extinction (Bittante and Pastore, 1988; Ramanzin et al., 1991). In a parallel study conducted with the same animals, Bittante et al. (2014) showed that milk composition of the major nutrients was not affected by the breed of ewes, with the only exception being a slightly lower content of nonfat solids of milk from Lamon compared with that from Foza ewes (11.7 vs. $12.1 \%$, respectively; $P=0.05$ ).

In the current paper, considering that the typical flavor of sheep milk and cheese is influenced by the presence of some FA (Guinee and O'Brien, 2010) and that the current literature on sheep milk commonly reports data on only a limited number of major FA, we focused on achieving a detailed FA profile of milk and evaluating the effects of breed and other possible sources of variation. The present study confirmed the greater contents of short-chain, even-numbered, and not-branched SFA in milk from sheep compared with that from cows, factors that are considered responsible for the typical piquant flavor of Pecorino-type cheese (Guinee and O'Brien, 2010). The sheep milk FA profile in the current experiment also had lesser proportions of C16:0, C18:0, and C18:1 FA compared with the values commonly found in bovine milk.

The effects of breed on the FA profile of sheep milk have been the focus of some studies with contradictory results, and none has studied the autochthonous sheep breeds of northeast Italy. Signorelli et al. (2008) found differences in the milk FA profile $(15 \mathrm{FA}$ and $3 \mathrm{FA}$ categories) among 3 southern Italian sheep breeds kept on pasture, under conditions different from those of current experiment. They observed that Sarda, a specialized 
Table 6. Effects of rumen-protected CLA supplementation and sampling period on the proportion of milk MUFA and PUFA (g/100 g of FA) from 3 native sheep breeds of the Veneto Alps (FA are listed in order of elution)

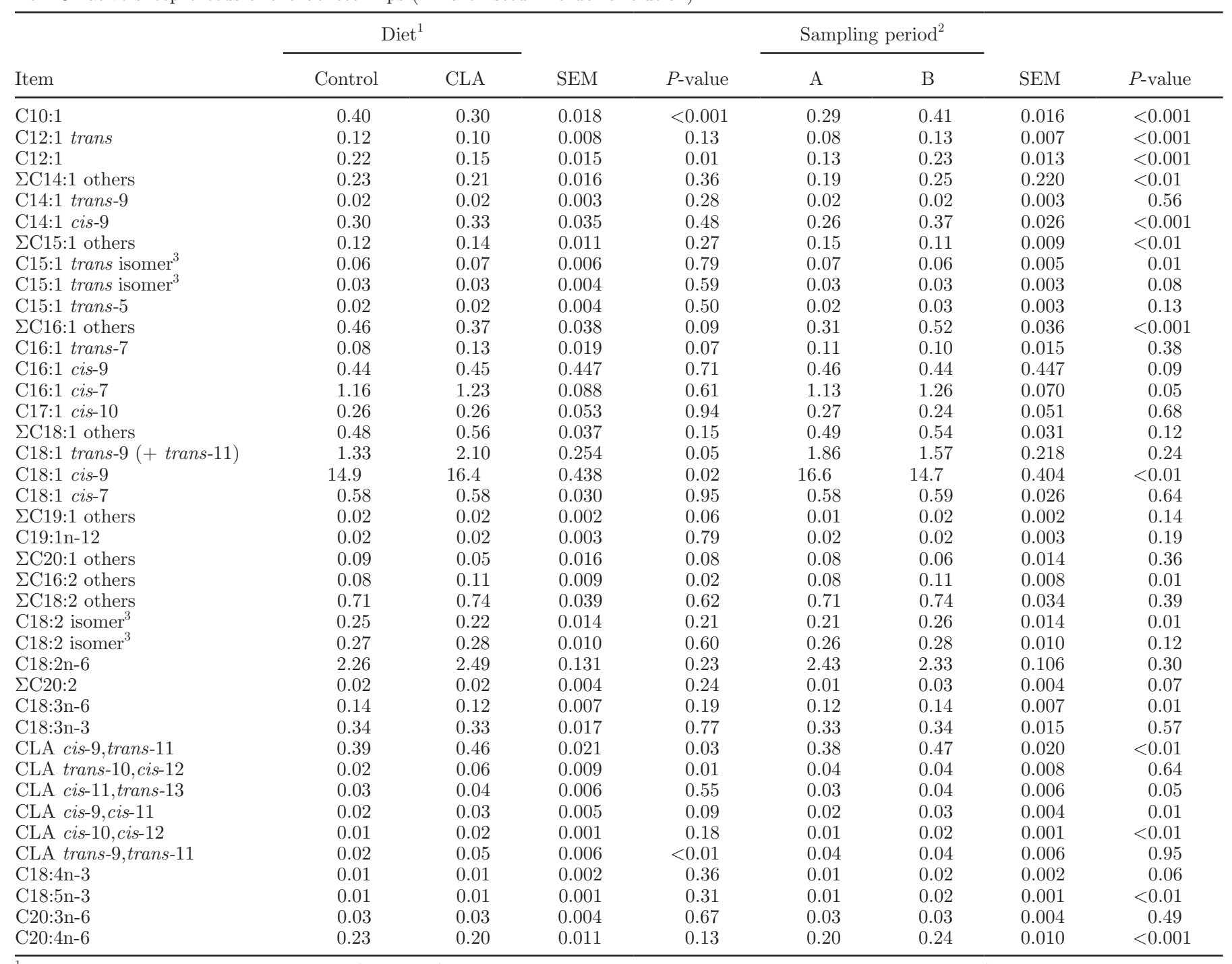

${ }^{1}$ Data are least squares means resulting from the following design: 3 breeds $\times 2$ diets $\times 2$ to 6 ewes $\times 2$ periods of milk sampling $\times 2$ analytical replications. The CLA diet was obtained by top dressing the control diet with $12 \mathrm{~g} / \mathrm{d}$ per ewe plus $4 \mathrm{~g} / \mathrm{d}$ for each lamb older than $30 \mathrm{~d}$ of a commercial CLA mixture (SILA, Noale, Italy).

${ }^{2}$ Periods A and B indicate milk samples collected during the first and second months of trial, respectively.

${ }^{3}$ Isomers partially identified from their position in the 2-dimensional chromatograms.

dairy breed, showed a FA profile with smaller proportions of short-chain SFA and of MUFA with 10, 14, and 16 carbon chains and greater proportions of C18:0 compared with the local (not specialized) Altamurana and Gentile di Puglia sheep breeds. In the current study, none of these FA was affected by breed, but breed influenced the proportions of odd- and branched-chain FA and some PUFA (Tables 3 and 4), data that were not given (odd- and branched-chain FA) or given only as a group (C18:2 and C18:3) or as individual CLA isomer (CLA $c 9, t 11$ ) in the paper of Signorelli et al. (2008).
Tsiplakou et al. (2008) compared the milk FA profile (16 FA, 5 FA categories) of ewes of Awassi, Lacaune, Friesland, and Chios breeds (very different in origin and characteristics among themselves) kept on indoor diets during winter and on pasture during spring. They found that milk yield and FA profile were poorly or not influenced by breed but notably affected by season/ feeding system. They often found a significant breed $\times$ season/feeding system interaction on these traits, reflecting a different magnitude of breed response to seasonal/dietary factors, but not opposite trends. Mi- 
Table 7. Effects of rumen-protected CLA supply and sampling period on milk fat content (\%) and on the proportion of various categories of milk FA ( $\mathrm{g} / 100 \mathrm{~g}$ of FA) and some indices of 3 native breeds of the Veneto Alps

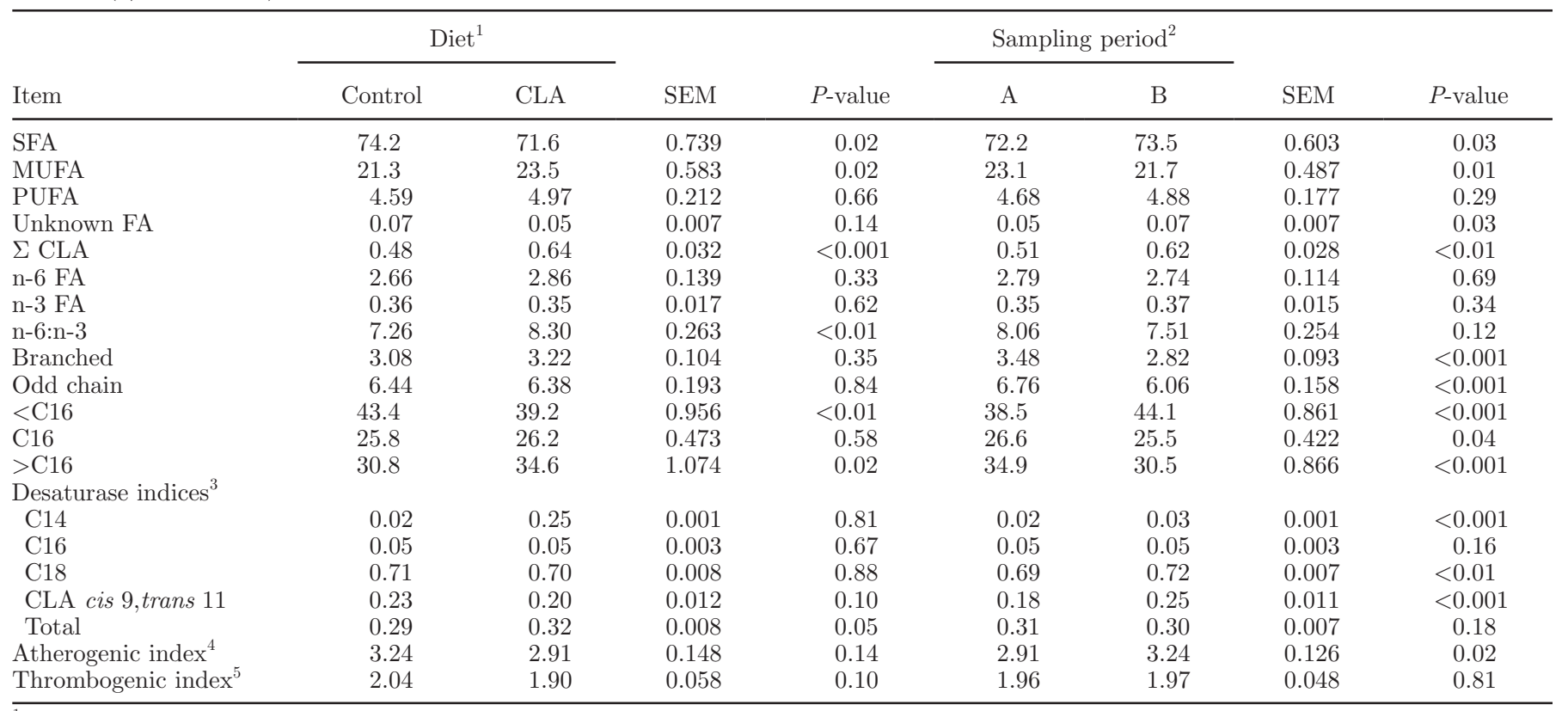

${ }^{1}$ Data are least squares means resulting from the following design: 3 breeds $\times 2$ diets $\times 2$ to 6 ewes $\times 2$ periods of milk sampling $\times 2$ analytical replications. The CLA diet was obtained by top dressing the control diet with $12 \mathrm{~g} / \mathrm{d}$ per ewe plus $4 \mathrm{~g} / \mathrm{d}$ for each lamb older than $30 \mathrm{~d}$ of a commercial CLA mixture (SILA, Noale, Italy).

${ }^{2}$ Periods A and B indicate milk samples collected during the first and second months of trial, respectively.

${ }^{3}$ Computed according to Kelsey et al. (2003).

${ }^{4}$ Computed according to Ulbricht and Southgate (1991).

erlita et al. (2011) found greater differences in milk FA profile (23 FA, 7 FA categories, and 4 indices) due to breed (Spanca and Turcana, Romania) compared with those found in the current study. The major differences between those breeds regarded the even-numbered SFA from C6 to C16, C18:1 $c 9$ and C18:2,t11, CLA $c 9, t 11$, and all groups and indices, except the n-6:n-3 FA ratio. Recently, Soják et al. (2013) found that milk FA profile (15 FA, 6 groups and 2 indices) of Lacaune, a specialized sheep dairy breed of French origin, showed greater proportions of $\mathrm{C} 10: 0, \mathrm{C} 12: 0$, and $\mathrm{C} 14: 0$ and smaller proportions of $\mathrm{C} 4: 0, \mathrm{C} 16: 0, \mathrm{C} 16: 1 \quad c 9$, and $\mathrm{C} 18: 1 \quad c 9$ compared with 2 Slovakian breeds, Tsigai and Improved Valachian, with sheep kept on pasture. In agreement with current study, Soják et al. (2013) found no breed effect on n- 6 and n-3 FA proportions, even if the dairy sheep breed showed slightly lower desaturase indices compared with local breeds. In the present study, we observed that Brogna had a lesser amount of C18:2 $c 9, t 11$ compared with the Foza and Lamon sheep.

The results of this study suggest that, under the indoor feeding conditions applied in the current experiment, breed exerts a small effect on milk FA profile, mainly affecting proportions of odd- and branchedchain FA and some PUFA.

\section{Animal Within Breed Effect}

In the current experiment, despite small differences observed among breeds, milk FA profile was influenced by the individuals within breed. Animal repeatability was small for short-chain SFA (C4 to C13), mediumsmall for SFA with chains containing 14 to 19 carbon atoms, except C16:0 (Table 2), large for most MUFA, and medium-small for PUFA (Table 3). In the literature, few studies have analyzed the within-breed individual effect on milk FA profile. De La Fuente et al. (2009), following a different approach, found that individual ewe explained a greater fraction of milk FA profile variance than did age or lactation stage but a lesser fraction than that explained by flock and testing day. Variation among individuals was greater for SFA, except C16:0, than that observed for unsaturated FA, excluding CLA $c 9, c 11$. Soják et al. (2013) observed that the ranking of individual ewes for milk CLA content changed when sheep were moved from indoor feeding to pasture. In a large survey on a back-cross Sarda $\times$ Lacaune population, Carta et al. (2008) calculated the individual repeatability of milk FA proportion and obtained estimates ranging from 0.15 for the C18:3 FA group to almost 0.60 for $\mathrm{C} 4: 0$ and $\mathrm{C} 17: 0$. In addition, 
the desaturase indices were largely influenced by the individuals. In the study of Carta et al. (2008), the individual repeatability for most common FA differed by less than an order of magnitude, as we found in the current experiment. This suggests the existence of genetic variability for the milk FA profile, which might permit genetic selection to improve the quality of milk FA profile according to production aims and desired effects on human health. Results of Carta et al. (2008) support this possibility because they reported that sire variance, which corresponds to one-fourth of additive genetic variance, was seldom greater than $10 \%$ of total variance, and specifically for C4:0, C10:0, C12:0, C16:0, and C17:0, but it was never null. More recently, Sánchez et al. (2010) carried out a very large survey on Churra sheep in Spain to estimate the heritability of milk FA proportions. In general, heritability values were low $(<10 \%)$ and they were about half the values found for milk yield and fat and protein contents. The availability of new, powerful, and accurate analytical methods, such as GC $\times$ GC, as well as the possibility of using Fourier-transform infrared spectroscopy for analysis at the population level (Soyeurt et al., 2007; De Marchi et al., 2011; Bittante and Cecchinato, 2013), provide new opportunities to improve our knowledge of phenotypic and genetic aspects of the sheep milk FA profile. In addition, some authors have found significant associations between the proportion of some sheep milk FA and specific candidate genes (Moioli et al., 2012), so advances in molecular genetics may also contribute to our understanding of sheep milk FA profile.

\section{Effect of Supplying Rumen-Protected CLA}

The ability of CLA to regulate milk fat synthesis is commonly observed in different species, including humans (Bauman et al., 2008). Conjugated linoleic acids are produced as intermediates in the biohydrogenation of linoleic acid by rumen microbes. The predominant CLA isomer in ruminant milk fat is C18:2 $c 9, t 11$ (75-90\% of total CLA), and it arises mainly from endogenous synthesis via $\Delta^{9}$-desaturase in the mammary gland. Milk fat, however, contains most of the other 24 possible CLA isomers, albeit each at a level generally $1 \%$ or less of total CLA (Bauman et al., 2008). Nevertheless, the C18:2 $c 10, t 12$ isomer is found to be more effective in reducing milk fat yield, whereas C18:2 $c 9, t 11$ is about half as effective as C18:2 $c 10, t 12$ (Bauman et al. 2008). In lactating sheep, C18:2 t10,c12 supply decreased milk fat synthesis, similar to that observed in lactating dairy cows (Perfield et al., 2002; Pulina et al., 2006). Multiparous ewes in early lactation supplemented with lipid-encapsulated C18:2 t10,c12 CLA to provide $2.4 \mathrm{~g} / \mathrm{d}$ of this isomer had reductions in milk fat content from 6.4 to $4.9 \mathrm{~g} / 100 \mathrm{~mL}$ and fat yield from 95 to $80 \mathrm{~g} / \mathrm{d}$, but, interestingly, they had increases in milk yield from 1,471 to $1,611 \mathrm{~g} / \mathrm{d}$ and protein yield from 68 to $73 \mathrm{~g} / \mathrm{d}$, compared with the control group (Lock et al., 2006). In the current experiment, milk production was not measured, as the ewes were left suckling their offspring, whose growth rate was not affected by rpCLA supplementation. Therefore, we can make no inferences about possible variations in daily milk fat and protein yields. However, the ewes receiving rpCLA produced milk containing 0.3 percentage points less protein (but also 0.6 percentage points less fat, not significant) compared with those receiving the control diet (Figure 1). The inclusion of rpCLA altered the sheep milk FA profile, with notable reductions in the proportions of short-chain FA (C4:0 to C12:0) and of some MUFA such as C11:1, C12:1, C16:1, and increases in proportions of $\mathrm{C} 18: 1 \mathrm{FA}$ group, including vaccenic acid co-eluted with elaidic acid, and the proportions of various CLA. These results are in agreement with those found by Bauman and Griinari (2001), who showed that an abomasal infusion of $\mathrm{C} 18: 2 t 10, c 12$ decreased the proportion of de novo synthesized FA (those with carbon chains $\leq 16$ carbon atoms). Alteration of the FA profile due to the same rpCLA supplementation were not observed on liver, 2 fatty tissues, or 3 muscles in growing lambs (Pellattiero et al., 2015), so lipid metabolism of the mammary gland seems to be much more influenced by the presence of these isomers compared with other body tissues. The inclusion of rpCLA in the diet increased the milk FA proportion of C18:2 $c 9, t 11$ by $18 \%, 3$ times that of $\mathrm{C} 18: 2 t 10, c 12$, and similar increases were found in various tissues of growing lambs receiving the same rumen-protected CLA mixture (Pellattiero et al., 2015). The effectiveness of using rumenprotected CLA to transfer specific FA from feed to milk is supported by the results of current experiment.

\section{CONCLUSIONS}

Application of the GC $\times$ GC technique allowed us to obtain a very detailed FA profile in sheep milk, with about 170 different FA detected, even when present in very small concentrations. The rpCLA supply not only increased the presence of CLA in the sheep milk, but also affected lipid metabolism, as shown by the decreased proportion of de novo-synthesized shortchain FA in the udder. In addition, breed had small influences on milk FA profile, and the major difference among breeds involved branched- and odd-chain FA. However, because the number of sheep was small in this preliminary trial, further investigations are required to confirm our results. Within breed, animal repeatability for the relative presence of milk FA was notable for 
MUFA and for SFA with 14 to 19 carbon atoms, except C16:0, and less so for PUFA.

\section{ACKNOWLEDGMENTS}

The authors acknowledge the Veneto Region project Bionet (misura 214 - pagamenti agroambientali - sottomisura $\mathrm{H}$-Rete regionale della biodiversità) and the technical assistance of Alberto Simonetto and Luca Grigoletto [both of Department of Agronomy, Food, Natural Resources, Animals and Environment (DAFNAE), Legnaro, Italy]. We also thank SILA s.r.l. (Noale, Italy) for providing the rumen-protected CLA used in this experiment.

\section{REFERENCES}

Adahchour, M., J. Beens, and U. A. Brinkman. 2008. Recent developments in the application of comprehensive two-dimensional gas chromatography . J. Chromatogr. A 1186:67-108.

Bauman, D. E., J. W. Perfield II, K. J. Harvatine, and L. H. Baumgard. 2008. Regulation of fat synthesis by conjugated linoleic acid: Lactation and the ruminant model. J. Nutr. 138:403-409.

Bauman, D. E., and J. M. Griinari. 2001. Regulation and nutritional manipulation of milk fat: Low-fat milk syndrome. Livest. Prod. Sci. 70:15-29.

Bittante, G., and A. Cecchinato. 2013. Genetic analysis of the Fouriertransform infrared spectra of bovine milk with emphasis on individual wavelengths related to specific chemical bonds. J. Dairy Sci. 96:5991-6006.

Bittante, G., and E. Pastore. 1988. Effect of Finnsheep crossbreeding on Lamon sheep performance-In vivo traits. J. Agric. Sci. Finl. 60:511-514.

Bittante, G., E. Pellattiero, F. Malchiodi, C. Cipolat-Gotet, M. Pazzola, G. M. Vacca, S. Schiavon, and A. Cecchinato. 2014. Quality traits and modeling of coagulation, curd firming and syneresis of sheep's milk of Alpine breeds fed diets supplemented with rumen protected conjugated fatty acid (CLA). J. Dairy Sci. 97:40184028.

Buccioni, A., S. Rappacini, M. Antongiovanni, S. Minieri, G. Conte, and M. Mele. 2010. Conjugated linoleic acid and C18:1 isomers content in milk fat of sheep and their transfer to pecorino Toscano cheese. Int. Dairy J. 20:190-194

Carta, A., S. C. Asu, M. G. Usai, M. Addis, M. Fiori, A. Franghi, S. Miari, L. Mura, G. Piredda, L. Schibler, T. Sechi, J. M. Elsen, and F. Barillet. 2008. Investigating the genetic component of fatty acid content in sheep milk. Small Rumin. Res. 79:22-28.

Cattani, M., R. Mantovani, S. Schiavon, G. Bittante, and L. Bailoni. 2014. Recovery of n-3 polyunsaturated fatty acids and conjugated linoleic acids in ripened cheese obtained from milk of cows fed different levels of extruded flaxseed. J. Dairy Sci. 97:123-135.

Cesaro, G., L. Grigoletto, G. Bittante, and S. Schiavon. 2011. A comparison among analytical methods to assess fatty acids and conjugated linoleic acids (CLA) content and repeatability of ruminant faeces. Agriculturae Conspectus Scientificus 76:349-352.

Cesaro, G., F. Tagliapietra, L. Grigoletto, A. Cecchinato, D. Dannenberger, G. Bittante, and S. Schiavon. 2013. Fecal sample preparation methods for gas chromatography analysis of fatty acids of ruminants fed different amounts of rumen protected conjugated linoleic acids (CLA). Anim. Feed Sci. Technol. 183:184-194.

Chouinard, P. Y., L. Corneau, D. M. Barbano, L. E. Metzger, and D. E. Bauman. 1999. Conjugated linoleic acids alter milk fatty acid composition and inhibit milk fat secretion in dairy cows. J. Nutr. 129:1579-1584.
Christie, W. W. 2001. A practical guide to the analysis of conjugated linoleic acid (CLA). Inform 12:147-152.

Connor, W. E. 2000. Importance of n-3 fatty acids in health and disease. Am. J. Clin. Nutr. 71:171S-175S

FASS (Federation of Animal Science Societies). 1988. Guide for the Care and Use of Agricultural Animals in Agricultural Research and Teaching. 1st ed. FASS, Champaign, IL.

De La Fuente, L. F., E. Barbosa, J. A. Carriedo, C. Gonzalo, R. Arenas, J. M. Fresno, and F. San Primitivo. 2009. Factors affecting variation of fatty acid content in ovine milk. J. Dairy Sci. 92:3791-3799.

De Marchi, M., M. Penasa, A. Cecchinato, M. Mele, P. Secchiari, and G. Bittante. 2011. Effectiveness of mid-infrared spectroscopy to predict fatty acid composition of Brown Swiss bovine milk. Animal 5:1653-1658.

Dilzer, A., and Y. Park. 2012. Implication of conjugated linoleic acid (CLA) in human health. Crit. Rev. Food Sci. Nutr. 52:488-513.

Guinee, T. P., and B. O'Brien. 2010. The quality of milk for cheese manufacture. Pages 1-67 in Technology of Cheesemaking. 2nd ed. B. A. Law and A. Y. Tamime, ed. Blackwell Publishing Ltd., Ames, IA. http://onlinelibrary.wiley.com/doi/10.1002/9781444323740. fmatter/pdf.

Hara, A., and N. S. Radin. 1978. Lipid extraction of tissues with a low-toxicity solvent. Anal. Biochem. 90:420-426.

Jutzeler van Wijlen, R. P., and P. C. Colombani. 2010. Grass-based ruminant production methods and human bioconversion of vaccenic acid with estimations of maximal dietary intake of conjugated linoleic acids. Int. Dairy J. 20:433-448.

Kelsey, J. A., B. A. Corl, R. J. Collier, and D. E. Bauman. 2003. The effect of breed, parity, and stage of lactation on conjugated linoleic acid (CLA) in milk fat from dairy cows. J. Dairy Sci. $86: 2588-2597$

Lock, A. L., B. M. Teles, J. W. Perfield II, D. E. Bauman, and L. A. Sinclair. 2006. A conjugated linoleic acid supplement containing trans-10, cis-12 reduces milk fat synthesis in lactating sheep. J. Dairy Sci. 89:1525-1532.

Maechler, M., P. Rousseeuw, A. Struyf, M. Hubert, and K. Hornik. 2012. Cluster: Cluster analysis basics and extensions. R package version 1.14.2. R Development Core Team, Vienna, Austria.

Manzano, P., E. Arnáiz, J. C. Diego, L. Toribio, C. García-Viguera, J. L. Bernal, and J. Bernal. 2011. Comprehensive two-dimensional gas chromatography with capillary flow modulation to separate FAME isomers. J. Chromatogr. A 1218:4952-4959.

Mierlita, D., St. Daraban, and F. Lup. 2011. Effects of breed on milk fatty acid profile in dairy ewes, with particular reference to cis9,trans-11 conjugated linoleic acid. S. Afr. J. Anim. Sci. 41:223231.

Mir, Z., M. L. Rushfeld, P. S. Mir, L. J. Paterson, and R. J. Weselake. 2000. Effect of dietary supplementation with either conjugated linoleic acid (CLA) or linoleic acid rich oil on the CLA content of lamb tissues. Small Rumin. Res. 36:25-31.

Moioli, B., G. Contarini, L. Pariset, C. Marchitelli, A. Crisà, G. Catillo, and F. Napolitano. 2012. Genetic variation of C18:1 and C18:2 isomers in sheep milk fat. Small Rumin. Res. 103:187-193.

Nudda, A., M. A. McGuire, G. Battacone, and G. Pulina. 2005. Seasonal variation in conjugated linoleic acid and vaccenic acid in milk fat of sheep and its transfer to cheese and ricotta. J. Dairy Sci. 88:1311-1319.

Or-Rashid, M. M., N. E. Odongo, and B. W. McBride. 2007. Fatty acid composition of ruminal bacteria and protozoa, with emphasis on conjugated linoleic acid, vaccenic acid, and odd-chain and branched-chain fatty acids. J. Anim. Sci. 85:1228-1234.

Pappritz, J., U. Meyer, R. Kramer, E. M. Weber, G. Jahreis, J. Rehage, G. Flachowsky, and S. Danicke. 2011. Effects of long-term supplementation of dairy cow rations with rumen-protected conjugated linoleic acids (CLA) on performance, metabolic parameters and fatty acid distribution in milk fat. Arch. Anim. Nutr. 65:89-107.

Pastore, E. 2002. Le razze ovine autoctone del Veneto. Veneto Agricoltura ed., Legnaro (PD), Italy. 
Pellattiero, E., A. Cecchinato, M. De Marchi, M. Penasa, N. Tormen, S. Schiavon, M. Cassandro, and G. Bittante. 2011. Growth rate, slaughter traits and meat quality of lambs of three Alpine sheep breeds. Agriculturae Conspectus Scientificus 76:297-300.

Pellattiero, E., A. Cecchinato, F. Tagliapietra, S. Schiavon, and G. Bittante. 2015. Determination by GC $\times$ GC of fatty acid and conjugated linoleic acid (CLA) isomer profiles in six selected tissues of lambs fed on pasture or on indoor diets with and without rumen-protected CLA. J. Agric. Food Chem. 63:963-974. http:// dx.doi.org/10.1021/jf504956x.

Perfield, J. W. II, G. Bernal-Santos, T. R. Overton, and D. E. Bauman. 2002. Effects of dietary supplementation of rumen-protected conjugated linoleic acid in dairy cows during established lactation. J. Dairy Sci. 85:2609-2617.

Prandini, A., S. Sigolo, G. Tansini, N. Brogna, and G. Piva. 2007. Different level of conjugated linoleic acid (CLA) in dairy product from Italy. J. Food Compos. Anal. 20:472-479.

Pulina, G., A. Nudda, G. Battacone, and A. Cannas. 2006. Effects of nutrition on the contents of fat, protein, somatic cells, aromatic compounds, and undesirable substances in sheep milk. Anim. Feed Sci. Technol. 131:255-291.

R Development Core Team. 2009. R: A language and environment for statistical computing. R Foundation for Statistical Computing, Vienna, Austria.

Raes, K., S. De Smet, and D. Demeyer. 2004. Effect of dietary fatty acids on incorporation of long chain polyunsaturated fatty acids and conjugated linoleic acid in lamb, beef and pork meat: A review. Anim. Feed Sci. Technol. 113:199-221.

Ramanzin, M., G. Bittante, and L. Bailoni. 1991. Evaluation of different chromium-mordanted wheat straws for passage rate studies. J. Dairy Sci. 74:2989-2996.

Sánchez, J. P., F. San Primitivo, E. Barbosa, L. Varona, and L. F. de la Fuente. 2010. Genetic determination of fatty acid composition in Spanish Churra sheep milk. J. Dairy Sci. 93:330-339.

Schiavon, S., M. De Marchi, F. Tagliapietra, L. Bailoni, A. Cecchinato, and G. Bittante. 2011. Effect of high or low protein ration combined or not with rumen protected conjugated-linoleic acid (CLA) on meat CLA content and quality traits of double-muscled Piemontese bulls. Meat Sci. 89:133-142.

Schiavon, S., F. Tagliapietra, M. Dal Maso, L. Bailoni, and G. Bittante. 2010. Effects of low-protein diets and rumen-protected con- jugated linoleic acid on production and carcass traits of growing double-muscled Piemontese bulls. J. Anim. Sci. 88:3372-3383.

Shingfield, K. J., M. Bonnet, and N. D. Scollan. 2013. Recent developments in altering the fatty acid composition of ruminant-derived food. Animal 7:132-162.

Signorelli, F., G. Contarini, G. Annicchiarico, F. Napolitano, L. Orrù, G. Catillo, G. F. W. Haenlein, and B. Moioli. 2008. Breed differences in sheep milk fatty acid profiles: Opportunities for sustainable use of animal genetic resources. Small Rumin. Res. 78:24-31.

Sinclair, L. A. 2007. Nutritional manipulation of the fatty acid composition of sheep meat: A review. J. Agric. Sci. 145:419-434.

Soják, L., J. Blaško, R. Kubinec, R. Górová, G. Addová, I. Ostrovský, and M. Margetín. 2013. Variation among individuals, breeds, parities and milk fatty acid profile and milk yield of ewes grazed on pasture. Small Rumin. Res. 109:173-181.

Soyeurt, H., A. Gillon, S. Vanderick, P. Mayeres, C. Bertozzi, and N. Gengler. 2007. Estimation of heritability and genetic correlations for the major fatty acids in bovine milk. J. Dairy Sci. 90:44354442

Terré, M., A. Nudda, F. Boe, G. Gaias, and A. Bach. 2011. Performance, immune response and fatty acid profile in lambs supplemented with a CLA-mixture. Anim. Feed Sci. Technol. 165:1-7.

Tsiplakou, E., A. Kominakis, and G. Zervas. 2008. The interaction between breed and diet on CLA and fatty acids content of milk fat of four sheep breeds kept indoors or at grass. Small Rumin. Res. 74:179-187.

Ulbricht, T. L. V., and D. A. T. Southgate. 1991. Coronary heart disease: Seven dietary factors. Lancet 338:985-992.

Vlaeminck, B., J. Harynuk, V. Fievez, and P. Marriot. 2007. Comprehensive two-dimensional gas chromatography for the separation of fatty acids in milk. Eur. J. Lipid Sci. Technol. 109:757-766.

Weerasinghe, W. M. P. B., R. G. Wilkinson, A. L. Lock, M. J. De Veth, D. E. Bauman, and L. A. Sinclair. 2012. Effect of a supplement containing trans-10, cis-12 conjugated linoleic acid on the performance of dairy ewes fed 2 levels of metabolizable protein and at a restricted energy intake. J. Dairy Sci. 95:109-116.

Wahle, K. W. J., S. D. Heys, and D. Rotondo. 2004. Conjugated linoleic acids: Are they beneficial or detrimental to health? Prog. Lipid Res. 43:553-587. 